number of behavioral problems at 1 year follow-up when compared with a randomly selected sample of children, ages 6 to 16 years. (Greenspan AI, MacKenzie EJ. Functional outcome after pediatric head injury. Pediatrics October 1994;94:425-432). (Reprints: Dr Arlene I Greenspan, National Center for Injury Prevention and Control, Centers for Disease Control and Prevention, 4770 Buford Highway, NE, Mailstop F-41, Chamblee, GA 30341).

COMMENT. In children who sustain head injury, the severity of the injury is correlated with preinjury health status, and even those with minor injuries have a greater incidence of chronic health problems than the general population. The risk of post-injury functional limitations was increased in children with a history of chronic illhealth and those who sustained lower extremity injuries. Evidence of cognitive, physical, or behavioral dysfunction requires intervention and rehabilitation.

The frequency of postconcussive symptoms in 41 children (ages 6-12) with traumatic brain injury (TBI) was evaluated at the Dept of Psychology, Case Western Reserve University, Cleveland, OH. Compared to 40 controls with orthopedic injuries only, those with TBI had more postconcussive symptoms both at baseline and at 6 month follow-up. The number of symptoms was related to injury severity and initial loss of consciousness (GCS <9), Nonverbal IQ and the baseline Children's Depression Inventory. (Barry CT, Klein SK, Taylor HG. Validity of postconcussive symptoms in children with traumatic brain injury. Ann Neurol Sept 1994;36:519 [abstr]).

\title{
EPIDURAL HEMATOMA ACCIDENTAL INJURY
}

A 7 -month-old infant who suffered a fall from a washing machine and sustained a frontal epidural hematoma is reported from the Division of Neurosurgery, Oregon Health Sciences University. The infant had been placed on an engaged washing machine strapped in his car seat and left unattended. Within 2 hours of the fall, the infant became more irritable, vomited, was listless, and had a generalized seizure. CT showed a fracture of the skull and a epidural hematoma. He was discharged on postoperative day 3 , and his development at 13 month of age was normal. Awareness of the potential consequences of this apparently popular and physician-endorsed childconsoling practice is important for physicians who must distinguish accident from abuse. (Hulka F, Piatt J. An infant in a car seat on a washing machine: epidural hematoma. Pediatrics October 1994;94:556-557).

COMMENT. Placement of infants in car seats on vibrating elevated surfaces might have a desired soporific effect but the practice carries the risk of falls and serious head injury. More than two-thirds of brain injuries in infants are attributable to falls, and epidural hematomas occur in 3\%. (Ped Neur Briefs Sept 1992). The rule that children falling from elevated household surfaces do not sustain serious injuries does not apply when an infant is buckled into a car seat. Righting reflexes are vitiated and the weight of the car seat adds to the impact.

Brain injury due to amniocentesis is reported in 4 children with hemiparesis and porencephalic cysts evaluated at Bowman Gray School 
of Medicine, Winston-Salem, NC. (Kandt RS, DeLong GR. Ann Neurol Sept $1994 ; 36: 516$ [abstr]).

\section{HEADACHE}

\section{PREVALENCE OF MIGRAINE IN SCHOOLCHILDREN}

The prevalence of migraine in a random sample of the childhood population of the city of Aberdeen, Scotland, was evaluated in the Department of Medical Paediatrics, Royal Aberdeen Children's Hospital, employing the International Headache Society Diagnostic Criteria and validating questionnaire responses with clinical interviews. Among 206 children diagnosed at interview, the causes of severe headache and their prevalence rates $(-\%)$ were as follows: migraine in $159(10.6 \%)$. migraine-like headache $(<2$ hours) in $10(0.7 \%)$, tension headache in $14(0.9 \%)$, non-specific in 20 $(1.3 \%)$, and sinusitis or other specific diagnosis in $3(0.2 \%)$. The prevalence of migraine increased with age, with male preponderance in children $<12$ years, and female preponderance $>12$ years of age. Children with migraine lost a mean of 8 school days a year ( 3 due to headache) as compared to 3 lost by controls. (Abu-Arefeh I, Russell G. Prevalence of headache and migraine in schoolchildren. BMI $2+$ Sept 1994;309:765-769). (Respond: Dr I Abu-Arefeh, Department of Child Health, University of Aberdeen, Aberdeen AB9 2ZD, UK).

COMMENT. Migraine is a common cause of headache among schoolchildren in Aberdeen, with a prevalence of about $11 \%$. This is more than twice the prevalence reported in some previous pediatric studies, comparable to the cited increased prevalence of migraine from 25 to $40 \%$ in an adult population in the US in recent years.

Environmental factors are thought to be responsible.

\section{INTER-OBSERVER AGREEMENT IN HEADACHE DIAGNOSIS}

Inter-observer agreement among 4 pediatric neurologists in the diagnosis of recurrent headaches in 40 children, ages 4 to 17 years (mean 10 years), was prospectively assessed at the University of Manitoba, Winnipeg, Canada. Referring to letters containing reports of the child's symptoms, history and examination, the headache diagnoses were checked off on a data sheet, listing up to 12 types. Agreement in headache diagnoses between pairs of neurologists ranged from $45 \%$ to $78 \%$. Agreement was $76 \%$ when both neurologists in a pair diagnosed single headache types, but only $4 \%$ when multiple diagnoses were applied. (Wolstein JR, Seshia SS et al. Inter-observer agreement in the diagnosis of childhood headache. Headache Sept 1994;34:467470). (Respond: SS Seshia MD, Section of Pediatric Neurosciences, AE-208 Children's Hospital, 840 Sherbrook St, Winnipeg, MB, R3A 1S1, Canada).

COMMENT. Agreement among pediatric neurologists was relatively good provided that a single headache type was diagnosed. The International Headache Society recommendations for classification of all headache types in a single patient may lower inter-observer agreement on diagnoses in children. For purpose of evaluation of pharmacological, dietary, or psychosocial treatment regimens, selection of patients with a single headache diagnosis is important. The validity of the classification criteria for childhood headache may need to be re-examined. 